\title{
The Relation Tensile Strength And Flexibility Of Bamboo For Soil Stabilization
}

\author{
Khoiriya Latifah $^{1 *}$, Joko Siswanto ${ }^{2}$, Bambang Supriyadi ${ }^{3}$, Carsoni $^{4}$ \\ ${ }^{1,3,4}$ Engineering and Informatics Department, Universitas PGRI Semarang, Jl. Sidodadi-Timur No.24 \\ Semarang, Central Java 50232, Indonesia \\ ${ }^{2}$ Physic Department, Universitas PGRI Semarang, Jl. Sidodadi-Timur No.24 Semarang, Central Java \\ 50232, Indonesia \\ * Corresponding author: khoiriyalatifah@upgris.ac.id
}

(Received: $31^{\text {st }}$ September 2019 ; Revised: $13^{\text {th }}$ April 2021 ; Accepted: $29^{\text {th }}$ April 2021)

\begin{abstract}
Bamboo is an abundant material and easily available in Indonesia. In addition to having high compressive strength and tensile strength as well as ease of obtaining and low prices, bamboo is a consideration and focus in developing in the world of construction today. In this study, bamboo is used for soil stabilization, where bamboo is used in the form of fibre. This research focuses on the strength properties of various types of bamboo. The focus is to investigate the relationship between the maximum tensile strength of bamboo and the flexibility of bamboo in soil stabilization. This is very important, because bamboo fibers used for soil stabilization rely on their tensile strength rather than their compressive strength. Thus, the optimum tensile strength and flexibility of bamboo must be of particular concern. From the results of the study of the tensile strength of two types of bamboo, namely Apus Bamboo and Java Bamboo, the Apus Bamboo results were found to have a higher tensile strength of 225.57 mpa with maximum flexibility of $19.99 \mathrm{~mm}$ and $43.76 \mathrm{mpa}$ for tensile strength of Javanese Bamboo with a level of flexibility of 10.26 $\mathrm{mm}$.
\end{abstract}

Keywords: Bamboo; tensile strength; flexibility; relationship

\section{Introduction}

Bamboo has a long and established history as a building material throughout the world in both the tropics and sub-tropics. According to Sharma in the world recorded more than 75 countries and 1250 species of bamboo, bamboo also grows abundantly throughout the Indonesian archipelago, and has been a part of Indonesian people's lives for centuries [1].

Many types of bamboo are found in Indonesia, there are approximately 75 types of bamboo, but only 10 species have economic value [2]. The types of bamboo that are often used for building construction in Indonesia include wulung bamboo, legi bamboo, petung bamboo, ampel bamboo.

At present wood, especially for durable class $1 \& 2$, is considered a high-priced building material. The scarcity factor of wood supply has pushed up the price of this material so that it is no longer affordable for most people who need housing or other buildings. This makes bamboo begin to be considered as a wood substitute building material.

Frick, H. states that this bamboo tree is classified in the family Gramineae (grass) which is somewhat different in nature from wood (trees)[3]. This bamboo plant has many advantages but there are also disadvantages when compared to wood. The advantage of bamboo material is that 
it is regenerative or can be cultivated again in a relatively short time compared to wood. Adult bamboo can be used optimally at around 3-5 years of age while new teak can be used optimally at the age of 30 years. In addition to its regenerative nature, Janssen J.A. explained that bamboo forests can also absorb $\mathrm{CO} 2$ levels of 62 tons / hectare / year while other new plantations can only absorb around 15 tons / hectare / year so that bamboo plants indirectly release oxygen (O2) as a result of photosynthesis $35 \%$ more than other trees [4][5].

The disadvantages of this bamboo plant are its resistance to the attack of the powder beetle, the signs of which are powdery flour and the appearance of small holes around the bamboo books / segments. This pest attack makes bamboo life short, so to be able to utilize bamboo optimally, it must use special bamboo preservation technology [6].

Bamboo is an environmentally friendly "wood" because bamboo grows faster than tree plants that produce wood. Bamboo can be harvested sustainably without having to turn off clumps that can damage the environment as well as logging tropical forests. Bamboo clumps can be harvested continuously without losing their function as carbon sinks, water binders and soil protectors from erosion[7].

Betung bamboo has a sympodial type with a fairly dense clump, reed height reaches 20-30 meters, base diameter of $20-30 \mathrm{~cm}$ with a length of $40-60 \mathrm{~cm}$, reed walls quite thick $11-38 \mathrm{~mm}$ and the length of the midrib $20-25 \mathrm{~cm}$, and has a larger primary branch compared to other branches [8]. Generally, bamboo grows well in soils with a $\mathrm{pH}$ of 5.0 to 6.5. In fertile soils, bamboo plants will grow well because the required mineral nutrients are met [9].

The price of bamboo is also relatively cheap when compared with wood material. Bamboo grows in almost all islands in Indonesia, from Sumatra to Papua. Even in many places bamboo resources are very abundant and neglected due to lack of expertise and knowledge in their use.

Based on research by Prof. Morisco from UGM, the power of bamboo can be juxtaposed with steel [10]. In addition, due to the flexible and elastic character of bamboo buildings, bamboo structures have been recognized and proven to be structures that are resistant to shocks, so that they are more secure and can reduce the risk of material loss when an earthquake occurs [11].

Because of the flexible and elastic character of bamboo buildings, it can be used for soil stabilization. Bamboo which is used for soil stabilization should have a good tensile strength and flexibility to stand the soil. In this research, the main topic is to know the relationship beetwen tensile strength and flexibility of bamboo which will be used for soil stabilization.

\section{Problem Formulation}

Based on the background study, this particular study aimed at finding out the relation between tensile strength and flexibility of bamboo and to find which parts of bamboo which have good relation between tensile strength and flexibility of bamboo which will be used for soil stabilization.

\section{Research Methodology}

\subsection{Sample Preparation}

There are 2 kinds of bamboo which are used, that is Java and Apus Bamboo. Each bamboo has 3 parts schematic sampling of bamboo stems, that is top, middle and bottom part and each part has 3 samples. In total there are 24 bamboo samples. Each bamboo is cut to a size of 2 times of diameter size in height. 


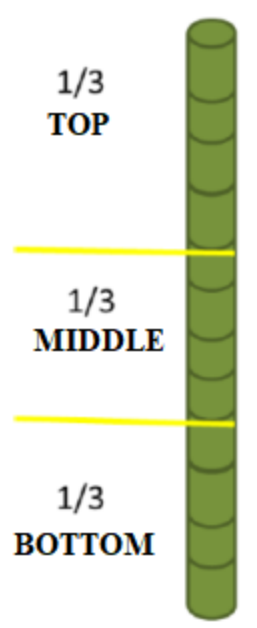

Fig. 1. Schematic sampling of bamboo stems

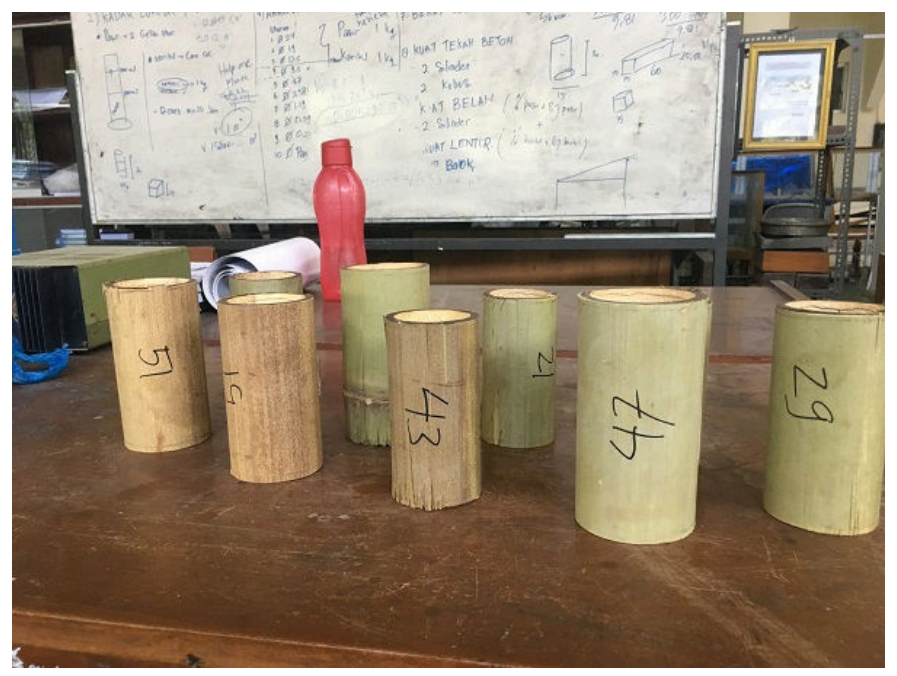

Fig. 2. Bamboo Samples

\subsection{Tensile Strength Test}

Bamboo is able to resist more tension than compression [12]. The tensile strength of a bamboo is a measure of the strength of a bamboo in terms of its ability to withstand the inclined forces causing the bamboo to separate from one another. Tensile strength can be divided into two types, namely the tensile strength of perpendicular fibers and parallel tensile strength of fibers. The tensile strength parallel to the direction of the fiber is the greatest tensile strength on bamboo [13]. The tensile strength of the perpendicular fibers has a relationship with bamboo resistance to division. The formula used to determine the tensile strength of bamboo according to SNI 07-2529$1991[14]$ is as follows:

$$
\mathrm{F}=\frac{P}{\boldsymbol{A}}
$$

Where:

$\mathrm{F} \quad=$ Tensile Strength (Mpa)

$\mathrm{P}=$ Maximum Force (kgf)

A $=$ Area $\left(\mathrm{mm}^{2}\right)$ 
The tensile strength test is carried out by using tensile strength test machine as follows :

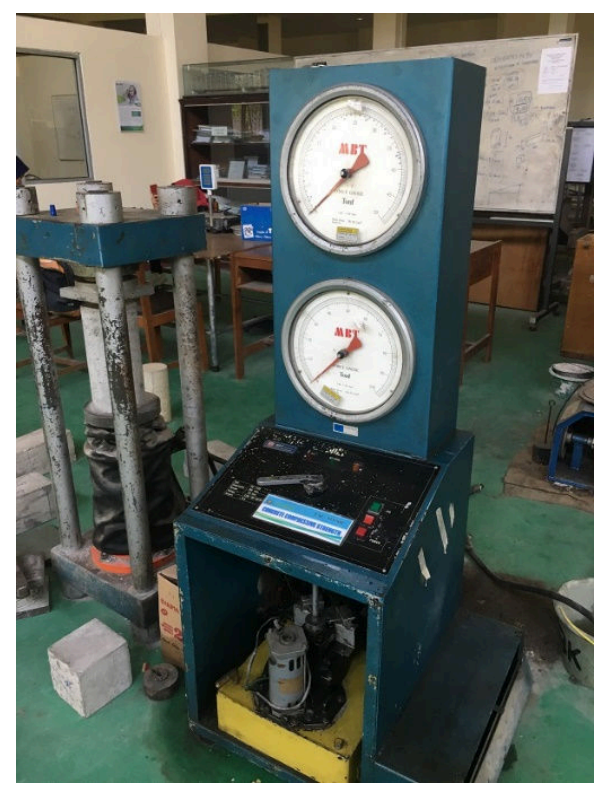

Fig. 3. Tensile and Compressive Test Machine

\section{Result}

The result of tensile strength and flexibility of bamboo are reported on Table 1-6 and there are 2 kinds of bamboo which is used, that is Java and Apus Bamboo.

Table 1. Tensile Strength and Flexibility of Java Bamboo 1

\begin{tabular}{lccccccc}
\hline & & \multicolumn{5}{c}{ Java Bamboo } \\
\cline { 3 - 7 } No & \multirow{2}{*}{ Classification } & \multicolumn{5}{c}{ Java Bamboo 1 } \\
\cline { 3 - 7 } & & \multicolumn{2}{c}{ Bottom } & \multicolumn{2}{c}{ Middle } & Top \\
\cline { 3 - 8 } & & 1 & 2 & 1 & 1 & 2 \\
\hline $\mathbf{1}$ & Outer Diameter (cm) & 6.5 & 6.5 & 6 & 6 & 6 & 6 \\
\hline $\mathbf{2}$ & Outer Radius (cm) & 3.25 & 3.25 & 3 & 3 & 3 & 3 \\
\hline $\mathbf{3}$ & Inner Diameter (cm) & 4 & 4.4 & 4.4 & 4.4 & 4.4 & 4.4 \\
\hline $\mathbf{4}$ & Inner Radius (cm) & 2 & 2.2 & 2.2 & 2.2 & 2.2 & 2.2 \\
\hline $\mathbf{5}$ & Height (cm) & 13 & 13 & 12 & 12 & 12 & 12 \\
\hline $\mathbf{6}$ & Weight (gr) & 235 & 185 & 130 & 175 & 140 & 110 \\
\hline $\mathbf{7}$ & Force (P) (kgf) & 535 & 599 & 684 & 610 & 366 & 414 \\
\hline $\mathbf{8}$ & Surface Area (A) (cm2) & 50.27 & 50.27 & 44.18 & 44.18 & 50.27 & 38.48 \\
\hline $\mathbf{9}$ & Tensile Strength (mpa) & 104.41 & 116.90 & 151.88 & 135.45 & 71.43 & 105.53 \\
\hline $\mathbf{1 0}$ & Flexibility (mm) & 26.9 & 21.36 & 26.25 & 25.51 & 32.18 & 22.72 \\
\hline
\end{tabular}


Table 2. Tensile Strength and Flexibility of Java Bamboo 2

\begin{tabular}{lccccccc}
\hline & & \multicolumn{5}{c}{ Java Bamboo } \\
\cline { 3 - 7 } No & \multirow{2}{*}{ Classification } & \multicolumn{5}{c}{ Java Bamboo 2 } \\
\cline { 3 - 7 } & & \multicolumn{2}{c}{ Bottom } & \multicolumn{5}{c}{ Middle } & Top \\
\cline { 3 - 7 } & & 1 & 2 & 1 & 1 \\
\hline $\mathbf{1}$ & Outer Diameter (cm) & 9.2 & 9.2 & 9 & 8.6 & 8 & 7.8 \\
\hline $\mathbf{2}$ & Outer Radius (cm) & 4.6 & 4.6 & 4.5 & 4.3 & 4 & 3.9 \\
\hline $\mathbf{3}$ & Inner Diameter (cm) & 7.5 & 7.5 & 7.2 & 7.1 & 6.1 & 6.1 \\
\hline $\mathbf{4}$ & Inner Radius (cm) & 3.75 & 3.75 & 3.6 & 3.55 & 3.05 & 3.05 \\
\hline $\mathbf{5}$ & Height (cm) & 15 & 15 & 15 & 15 & 15 & 15 \\
\hline $\mathbf{6}$ & Weight (gr) & 280 & 215 & 215 & 210 & 305 & 220 \\
\hline $\mathbf{7}$ & Force (kgf) & 530 & 684 & 461 & 445 & 944 & 589 \\
\hline $\mathbf{8}$ & Tensile Force (kN) & 10.54 & 13.61 & 16.30 & 11.56 & 21.37 & 11.72 \\
\hline $\mathbf{9}$ & Surface Area (A) (cm2) & 50.27 & 50.27 & 28.27 & 38.48 & 44.18 & 50.27 \\
\hline $\mathbf{1 0}$ & Tensile Strength (MPa) & 103.44 & 133.49 & 159.95 & 113.43 & 209.62 & 114.95 \\
\hline $\mathbf{1 1}$ & Flexibility (mm) & 22.44 & 23.53 & 20.36 & 17.97 & 29.14 & 24.63 \\
\hline & & & & & & &
\end{tabular}

Table 3. Tensile Strength and Flexibility of Java Bamboo 3

\begin{tabular}{cccccccc}
\hline & & \multicolumn{5}{c}{ Java Bamboo } \\
\cline { 3 - 7 } No & \multirow{2}{*}{ Classification } & \multicolumn{5}{c}{ Java Bamboo 3 } \\
\cline { 3 - 8 } & & 1 & 2 & 1 & 2 & 1 & 2 \\
\cline { 3 - 7 } & & 8.3 & 8.2 & 8 & 8 & 7.5 & 7.5 \\
\hline $\mathbf{1}$ & Outer Diameter (cm) & 8.2 & \multicolumn{7}{c}{ Middle } \\
\hline $\mathbf{2}$ & Outer Radius (cm) & 4.15 & 4.1 & 4 & 4 & 3.75 & 3.75 \\
\hline $\mathbf{3}$ & Inner Diameter (cm) & 5.8 & 5.8 & 6 & 6 & 6 & 6 \\
\hline $\mathbf{4}$ & Inner Radius (cm) & 2.9 & 2.9 & 3 & 3 & 3 & 3 \\
\hline $\mathbf{5}$ & Height (cm) & 15 & 15 & 15 & 15 & 15 & 15 \\
\hline $\mathbf{6}$ & Weight (gr) & 355 & 300 & 230 & 295 & 150 & 150 \\
\hline $\mathbf{7}$ & Force (P) (kgf) & 896 & 1135 & 933 & 885 & 695 & 774 \\
\hline $\mathbf{8}$ & Tarikan (P) (kN) & 9.43 & 17.84 & 16.44 & 15.60 & 18.06 & 20.11 \\
\hline $\mathbf{9}$ & Surface Area (A) (cm2) & 95.03 & 63.62 & 56.75 & 56.75 & 38.48 & 38.48 \\
\hline $\mathbf{1 0}$ & Tensile Strength (mpa) & 92.49 & 175.02 & 161.30 & 152.99 & 177.16 & 197.30 \\
\hline $\mathbf{1 1}$ & Flexibility (mm) & 33.85 & 31.54 & 31.06 & 29.15 & 28.17 & 25.61 \\
\hline
\end{tabular}


Table 4. Tensile Strength and Flexibility of Apus Bamboo 1

\begin{tabular}{lccccccc}
\hline & & \multicolumn{5}{c}{ Apus Bamboo } \\
\cline { 3 - 8 } No & \multirow{2}{*}{ Classification } & \multicolumn{5}{c}{ Apus Bamboo 1 } \\
\cline { 3 - 8 } & & \multicolumn{2}{c}{ Bottom } & \multicolumn{5}{c}{ Middle } & Top \\
\cline { 3 - 8 } & & 1 & 2 & 1 & 1 & 2 \\
\hline $\mathbf{1}$ & Outer Diameter (cm) & 6 & 6 & 5.5 & 5.5 & 4.5 & 4.5 \\
\hline $\mathbf{2}$ & Outer Radius (cm) & 3 & 3 & 2.75 & 2.75 & 2.25 & 2.25 \\
\hline $\mathbf{3}$ & Inner Diameter (cm) & 4.8 & 4.8 & 4.2 & 4.2 & 3.8 & 3.7 \\
\hline $\mathbf{4}$ & Inner Radius (cm) & 2.4 & 2.4 & 2.1 & 2.1 & 1.9 & 1.85 \\
\hline $\mathbf{5}$ & Height (cm) & 12 & 12 & 11 & 11 & 9 & 9 \\
\hline $\mathbf{6}$ & Weight (gr) & 145 & 105 & 85 & 80 & 85 & 55 \\
\hline $\mathbf{7}$ & Force (P) (kgf) & 535 & 610 & 636 & 551 & 732 & 551 \\
\hline $\mathbf{8}$ & Tarikan (P) (kN) & 18.92 & 21.57 & 22.49 & 23.19 & 30.81 & 19.49 \\
\hline $\mathbf{9}$ & Surface Area (A) (cm2) & 28.27 & 28.27 & 28.27 & 23.76 & 23.76 & 28.27 \\
\hline $\mathbf{1 0}$ & Tensile Strength (mpa) & 185.62 & 211.64 & 220.67 & 227.51 & 302.25 & 191.17 \\
\hline $\mathbf{1 1}$ & Flexibility (mm) & 24.09 & 23.68 & 16.54 & 16.31 & 24.33 & 19.76 \\
\hline
\end{tabular}

Table 5. Tensile Strength and Flexibility of Java Bamboo 2

\begin{tabular}{|c|c|c|c|c|c|c|c|}
\hline \multirow{4}{*}{ No } & \multirow{4}{*}{ Classification } & \multicolumn{6}{|c|}{ Apus Bamboo } \\
\hline & & \multicolumn{6}{|c|}{ Apus Bamboo 2} \\
\hline & & \multicolumn{2}{|c|}{ Bottom } & \multicolumn{2}{|c|}{ Middle } & \multicolumn{2}{|c|}{ Top } \\
\hline & & 1 & 2 & 1 & 2 & 1 & 2 \\
\hline 1 & Outer Diameter $(\mathrm{cm})$ & 6 & 6 & 6 & 6 & 5.5 & 5.5 \\
\hline 2 & Outer Radius (cm) & 3 & 3 & 3 & 3 & 2.75 & 2.75 \\
\hline 3 & Inner Diameter $(\mathrm{cm})$ & 4.9 & 4.9 & 4.6 & 4.5 & 4.5 & 4.4 \\
\hline 4 & Inner Radius (cm) & 2.45 & 2.45 & 2.3 & 2.25 & 2.25 & 2.2 \\
\hline 5 & Height (cm) & 12 & 12 & 12 & 12 & 11 & 11 \\
\hline 6 & Weight (gr) & 115 & 110 & 140 & 110 & 85 & 80 \\
\hline 7 & Force $(\mathrm{P})(\mathrm{kgf})$ & 254 & 334 & 408 & 514 & 477 & 345 \\
\hline 8 & Tarikan $(\mathrm{P})(\mathrm{kN})$ & 10.69 & 10.07 & 12.30 & 18.18 & 14.37 & 17.57 \\
\hline 9 & Surface Area (A) $(\mathrm{cm} 2)$ & 23.76 & 33.18 & 33.18 & 28.27 & 33.18 & 19.64 \\
\hline 10 & Tensile Strength (mpa) & 104.88 & 98.74 & 120.62 & 178.34 & 141.02 & 172.37 \\
\hline 11 & Flexibility (mm) & 16.43 & 16.15 & 17.75 & 17.07 & 26.04 & 12.11 \\
\hline
\end{tabular}


Table 6. Tensile Strength and Flexibility of Java Bamboo 3

\begin{tabular}{lccccccc}
\hline & & \multicolumn{5}{c}{ Apus Bamboo } \\
\cline { 3 - 8 } No & \multirow{2}{*}{ Classification } & \multicolumn{5}{c}{ Apus Bamboo 3 } \\
\cline { 3 - 8 } & & \multicolumn{2}{c}{ Bottom } & \multicolumn{7}{c}{ Middle } & Top \\
\cline { 3 - 8 } & & 1 & 2 & 1 & 2 & 1 & 2 \\
\hline $\mathbf{1}$ & Outer Diameter (cm) & 6 & 6 & 5.75 & 5.75 & 5.5 & 5.5 \\
\hline $\mathbf{2}$ & Outer Radius (cm) & 3 & 3 & 2.875 & 2.875 & 2.75 & 2.75 \\
\hline $\mathbf{3}$ & Inner Diameter (cm) & 4.8 & 4.8 & 4.8 & 4.7 & 4.3 & 4.3 \\
\hline $\mathbf{4}$ & Inner Radius (cm) & 2.4 & 2.4 & 2.4 & 2.35 & 2.15 & 2.15 \\
\hline $\mathbf{5}$ & Height (cm) & 12 & 12 & 11.5 & 11.5 & 11 & 11 \\
\hline $\mathbf{6}$ & Weight (gr) & 70 & 110 & 60 & 60 & 50 & 50 \\
\hline $\mathbf{7}$ & Force (P) (kgf) & 2856 & 3060 & 2652 & 3060 & 2448 & 2550 \\
\hline $\mathbf{8}$ & Tarikan (P) (kN) & 18.92 & 18.92 & 18.92 & 18.92 & 18.92 & 18.92 \\
\hline $\mathbf{9}$ & Surface Area (A) (cm2) & 10.18 & 10.18 & 7.87 & 8.62 & 9.24 & 9.24 \\
\hline $\mathbf{1 0}$ & Tensile Strength (mpa) & 274.68 & 294.3 & 0 & 0 & 235.44 & 245.25 \\
\hline $\mathbf{1 1}$ & Flexibility (mm) & - & - & - & - & - & - \\
\hline
\end{tabular}

Table 7. Average Result of Tensile Strength and Flexibility of Java and Apus Bamboo

\begin{tabular}{cccccccc}
\hline \multirow{2}{*}{ No } & Classification & \multicolumn{3}{c}{ Tensile Strenght } & \multicolumn{3}{c}{ Flexibility } \\
\cline { 3 - 8 } & Bottom & Middle & Top & Bottom & Middle & Top \\
\hline \multirow{2}{1}{} & \multirow{2}{*}{ Java Bamboo } & 120.96 & 145.84 & 146.00 & 26.60 & 25.05 & 27.08 \\
\hline 2 & Apus Bamboo & 150.22 & 186.78 & 201.70 & 20.09 & 16.92 & 20.56 \\
\hline
\end{tabular}

From the table 7, it is indicated that the maximum tensile strength in Java Bamboo is $146 \mathrm{mpa}$ and Apus Bamboo has a better tensile strength, that is $201.7 \mathrm{mpa}$. And the best part of bamboo to use is the top part, since either in Java Bamboo or Apus Bamboo, the top part has the highest result of tensile strength. So do with the flexibility result, the top part has the highest result of flexibility of the bamboo.

From the result of Table 7, it can be made the relationship graph between tensile strength and flexibility which is showed in Figure 4 in below 


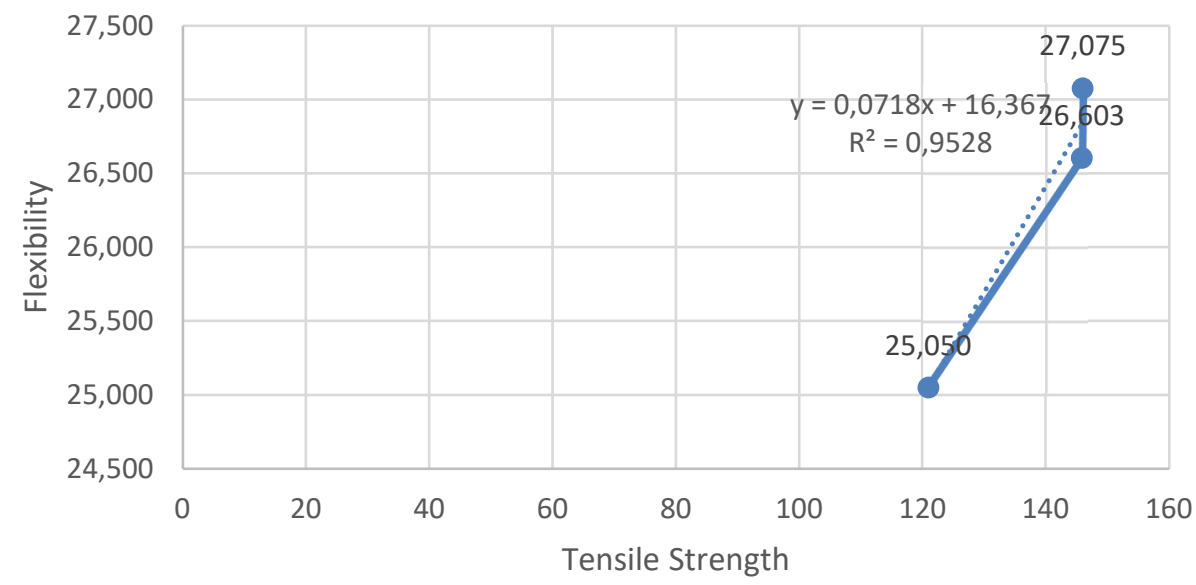

Figure 4. Relationship Graph of Tensile Strength and Flexibility

Calculation of constant values is as follows :

$$
\mathrm{Y}=0.0718 \mathrm{x}+16.367
$$

\section{Conclusion}

It comes to conclusion that Apus Bamboo has higher tensile strength test result with $201.7 \mathrm{mpa}$ and Java Bamboo has $146 \mathrm{mpa}$ in tensile strength. In Flexibility, Java Bamboo has higher result than Apus Bamboo, that is $27.08 \mathrm{~mm}$ for Java Bamboo and $20.56 \mathrm{~mm}$ for Apus Bamboo. The best part of bamboo to use is the top part, because from the experiments, it has the highest result both in tensile strength and flexibility result.

\section{Acknowledgments}

We would like to thank Direktorat Riset dan Pengabdian Masyarakat, Direktorat Jenderal Penguatan Riset dan Pengembangan from Kementerian Riset, Teknologi, dan Pendidikan Tinggi for funding this research through the "skim Penelitian Dasar Unggulan Perguruan Tinggi (PDUPT) 2018-2019".

\section{References}

[1] Sharma, Y.M.L. (1987), Bamboo in the Asia Pacific Region: 99-100, In Lessard, G. \& Chouinard. A. (eds) Bamboo Research in Asia. IDRC, Canada.

[2] Sutiyono (2007), Collection of Bamboo Species at the Bogor Forest Research and Development Center and Nature Conservation at the Arcamanik Forest Research Station, Bandung, in: Supporting paper on exposure of research results on conservation and rehabilitation of forest resources, Padang, Sept 20, 2006. Bogor: LIPI. pp.303 (in Indonesian).

[3] Frick, H. (2004), Bamboo Building Construction Science-An Introduction to Bamboo Construction, Yogyakarta: Kanisius (in Indonesian).

[4] Janssen, J. (1991), Mechanical Properties of Bamboo, Kluwer Academic Publishers, Dordecht, The Netherlands.

[5] Janssen, J.J. (2000), Designing and Building with Bamboo-Technical Report 20. International Network for Bamboo and Rattan, Beijing, China.

[6] Raj Denesh Ar, Agarwal Bindhu Ar (2014), Bamboo as a Building, Material Journal of Civil Engineering and Environmental Technology, Vol.1(3), pp. 56-61. 
[7] Latifa K, Supriyadi B and Rochim A (2018), Characteristics of Bamboo Fibre as Environmentally Friendly Material for Soil Strengthening, Advances in Social Science, Education and Humanities Research, Vol. 287, pp 18-21

[8] Dransfield; E.A. Widjaya, (1995), Plant Resources of South-East Asia no.7, Bamboos, Book, Prosea, Bogor, 189 p.

[9] Berlian, N.; E. Rahayu (1995), Types and Business Prospects of Bamboo, Penebar Swadaya, Jakarta, pp. 89 (in Indonesian).

[10] Kumar, P., \& Vasugi (2014). Study On Mechanical Strength Of Bamboo Reinforced Concrete Beams, International Journal of Advances in Science Engineering and Technology. , Vol. 2(3), pp. 103-105.

[11] Morisco (2005), Bamboo Technology, Program MTBB UGM Yogyakarta (in Indonesian).

[12] Ar Dhenesh Raj (2014), Bamboo As Building Materials https://www.krishisanskriti.org/vol image/03Jul201502074415.pdf

[13] Rina, Fahrina, 2014, Utilization of Betung Belitung Bangka Bamboo as a Substitute for Bamboo Reinforced Concrete Beams, http://journal.ubb.ac.id/index.php/fropil/article/view/269

[14] SNI 07-2529-1991, Steel Tensile Test Method, Department of Public Works (in Indonesian). 